\title{
Evaluation of noninvasive positive pressure ventilation after extubation from moderate positive end-expiratory pressure level in patients undergoing cardiovascular surgery: a prospective observational study
}

\author{
Takeshi Suzuki ${ }^{2 *}$, Takuya Kurazumi ${ }^{1}$, Shinya Toyonaga ${ }^{1}$, Yuya Masuda ${ }^{1}$, Yoshihisa Morita ${ }^{1}$, Junichi Masuda', \\ Shizuko Kosugi ${ }^{2}$, Nobuyuki Katori ${ }^{2}$ and Hiroshi Morisaki ${ }^{2}$
}

\begin{abstract}
Background: It remains to be clarified if the application of noninvasive positive pressure ventilation (NPPV) is effective after extubation in patients with hypoxemic respiratory failure who require the sufficient level of positive end-expiratory pressure (PEEP). This study was aimed at examining the effect and the safety of NPPV application following extubation in patients requiring moderate PEEP level for sufficient oxygenation after cardiovascular surgery.

Methods: With institutional ethic committee approval, the patients ventilated invasively for over $48 \mathrm{~h}$ after cardiovascular surgery were enrolled in this study. The patients who failed the first spontaneous breathing trial (SBT) at $5 \mathrm{cmH}_{2} \mathrm{O}$ of PEEP, but passed the second SBT at $8 \mathrm{cmH}_{2} \mathrm{O}$ of PEEP, received NPPV immediately after extubation following our weaning protocol. Respiratory parameters (partial pressure of arterial oxygen tension to inspiratory oxygen fraction ratio: $\mathrm{P} / \mathrm{F}$ ratio, respiratory ratio, and partial pressure of arterial carbon dioxide: $\left.\mathrm{Pa} \mathrm{CO}_{2}\right) 2 \mathrm{~h}$ after extubation were evaluated with those just before extubation as the primary outcome. The rate of re-intubation, the frequency of respiratory failure and intolerance of NPPV, the duration of NPPV, and the length of intensive care unit (ICU) stay were also recorded.
\end{abstract}

Results: While 51 postcardiovascular surgery patients were screened, 6 patients who met the criteria received NPPV after extubation. P/F ratio was increased significantly after extubation compared with that before extubation ( $325 \pm 85$ versus $245 \pm 55 \mathrm{mmHg}, p<0.05$ ). The other respiratory parameters did not change significantly. Re-intubation, respiratory failure, and intolerance of NPPV never occurred. The duration of NPPV and the length of ICU stay were $2.7 \pm 0.7$ (SD) and 7.5 (6 to 10) (interquartile range) days, respectively.

Conclusions: While further investigation should be warranted, NPPV could be applied effectively and safely after extubation in patients requiring the moderate PEEP level after cardiovascular surgery.

Keywords: Weaning, Invasive mechanical ventilation, Noninvasive positive pressure ventilation, Moderate PEEP level, Cardiovascular surgery

\footnotetext{
* Correspondence: takeshi-su@a7.keio.jp

${ }^{2}$ Department of Anesthesiology and General Intensive Care Unit, Keio University School of Medicine, 35 Shinanomachi, Shinjuku-ku, Tokyo 160-8582, Japan

Full list of author information is available at the end of the article
} 


\section{Background}

Prolonged invasive mechanical ventilation (IMV) through endotracheal tube, appreciated as the most efficient way to provide sufficient oxygenation in patients with respiratory failure, is ironically likely to cause various complications such as ventilator-induced lung injury and ventilatorassociated pneumonia, leading to an increase of mortality $[1,2]$. Thus, one of the major goals in the intensive care unit (ICU) is to wean critical ill patients from such IMV as early as possible without consequent respiratory failure and re-intubation. A number of clinical trials have demonstrated that the clinical strategy such as daily interruption of sedation [3], protocol-based sedation [4], and awaking and breathing trial [5] to obviate the prolonged duration of IMV is beneficial.

Previous studies showed that noninvasive positive pressure ventilation (NPPV) is safe and effective to facilitate weaning from IMV in especially medical patients requiring long-term ventilatory support for predominantly hypercapnic respiratory failure [6-8]. However, there are few data which describe the effectiveness of NPPV to facilitate the process of liberation from IMV in patients with hypoxemic respiratory failure. Due to severe postoperative pulmonary complications such as atelectasis, pulmonary edema, pneumonia, and phrenic nerve palsy, postcardiovascular surgery patients often develop hypoxemic respiratory failure requiring high level of positive end-expiratory pressure (PEEP) for sufficient oxygenation and could suffer from prolonged IMV $[9,10]$. Although NPPV has been used widely for postoperative respiratory failure $[11,12]$, there are few studies to examine whether NPPV can be applied effectively and safely after extubation in such population who requires sufficient PEEP level and longterm ventilator support after cardiovascular surgery.

We, therefore, designed the present study to evaluate the effect and the safety of our weaning protocol in which NPPV was applied after extubation in these patients who were mechanically ventilated for over $48 \mathrm{~h}$ and simultaneously required moderate PEEP level for sufficient oxygenation after cardiovascular surgery.

\section{Methods}

We conducted this prospective observational study in our eight-bed ICU of Kawasaki Municipal Hospital in Japan. Institutional review board approval was obtained and thereby allowed us to wave the need of informed consent since this is an observational study and the application of NPPV after extubation is performed in a routine manner in our ICU.

\section{Study protocol}

Patients who underwent cardiovascular surgery from April 2011 to December 2011 in our hospital were screened. All patients who received mechanical ventilation via endotracheal tube for over $48 \mathrm{~h}$ after cardiovascular surgery were enrolled in this study. Exclusion criteria were younger than 20 years old, body mass index over 35 , and chronic renal failure requiring hemodialysis. We excluded patients on hemodialysis since extubation from moderate PEEP level through NPPV application might be hazardous due to the impracticality of constant diuresis in these patients. Additionally, the patients who could not be weaned from IMV or died within 14 postoperative days (POD) were excluded from the study. Eligible patients were screened every morning and considered ready for weaning if they met all the following weaning criteria: (1) hemodynamic stability requiring less than $3 \mu \mathrm{g} / \mathrm{kg} / \mathrm{min}$ of dopamine or dobutamine and/or less than $0.02 \mu \mathrm{g} / \mathrm{kg} /$ min of norepinephrine, (2) partial pressure of arterial oxygen tension to inspiratory oxygen fraction ratio (P/F ratio) more than or equal to $200 \mathrm{mmHg}$ with PEEP of 10 $\mathrm{cmH}_{2} \mathrm{O}$ or less, (3) adequate conscious level and cough reflex, and (4) absence of hyperthermia $\left(>38^{\circ} \mathrm{C}\right)$ or suspected pneumonia. Pneumonia was suspected in patients with a new or worsened pulmonary infiltrate on chest X-ray who meets any two of the following three criteria: leukocyte count above 12,000 or below $4,000 / \mu \mathrm{L}$, body temperature above $38^{\circ} \mathrm{C}$ and/or the presence of purulent respiratory secretions. Patients who met all these weaning criteria were initiated to wean from IMV following our protocol (Figure 1). This protocol was quite different from the conventional one in which the trachea was extubated only after successful spontaneous breathing trial (SBT) at 5 $\mathrm{cmH}_{2} \mathrm{O}$ of PEEP.

The first SBT was performed under continuous positive airway pressure (CPAP) mode with pressure support (PS) for $2 \mathrm{~h}$ at the following setting: PEEP equal to $5 \mathrm{cmH}_{2} \mathrm{O}$, PS equal to $5 \mathrm{cmH}_{2} \mathrm{O}$, and inspiratory oxygen fraction $\left(\mathrm{FIO}_{2}\right)$ equal to or less than 0.5 . If the patients could tolerate the first SBT in accordance with our extubation criteria described below, the trachea was extubated. The extubation criteria were as follows: (1) P/F ratio $\geqq 200 \mathrm{mmHg}$, (2) respiratory ratio $<30 / \mathrm{min}$, (3) rapid shallow breathing index (the ratio of respiratory frequency to tidal volume) $<105$, (4) variability of blood pressure and heart rate $<20 \%$, (5) adequate conscious level and cough reflex, and (6) no agitation. If the first SBT failed, the second SBT was performed for $2 \mathrm{~h}$ at the following setting immediately after the first SBT followed by recruitment maneuver $\left(30 \mathrm{cmH}_{2} \mathrm{O}\right.$ for $\left.30 \mathrm{~s}\right)$ application, CPAP mode with PEEP equal to $8 \mathrm{cmH}_{2} \mathrm{O}$, PS equal to $5 \mathrm{cmH}_{2} \mathrm{O}$, and $\mathrm{FIO}_{2}$ equal to or less than 0.5. If the extubation criteria during the second SBT were confirmed, they received sequential NPPV (BiPAP vision, Respironics, Murrysvile, PA, USA) through a full facial mask immediately after extubation. NPPV was delivered at the CPAP mode with $8 \mathrm{cmH}_{2} \mathrm{O}$ of PEEP and the same $\mathrm{FIO}_{2}$ as before extubation. During NPPV, all patients were 


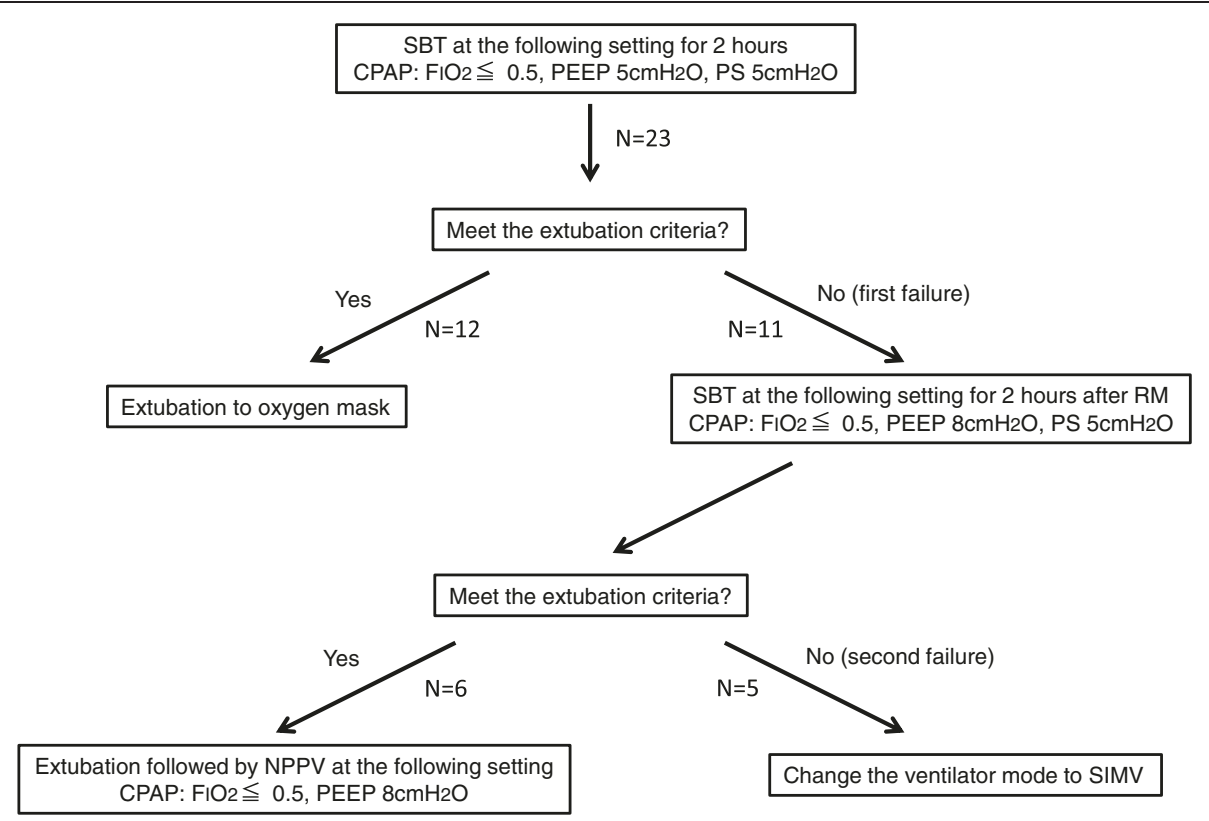

Figure 1 Study protocol for weaning from invasive ventilator support. SBT, spontaneous breathing trial; CPAP, continuous positive airway pressure; $\mathrm{FlO}_{2}$, inspiratory oxygen fraction; PEEP, positive end-expiratory pressure; PS, pressure support; $\mathrm{RM}$, recruitment maneuver, RM was performed at the pressure of $30 \mathrm{cmH}_{2} \mathrm{O}$ for $30 \mathrm{~s}$; SIMV, synchronized intermittent mandatory ventilation.

administered an infusion of dexmedetomidine $(0.2$ to $0.7 \mu \mathrm{g} / \mathrm{kg} / \mathrm{hr}$ ) to relieve discomfort. Ventilator setting was not changed for $2 \mathrm{~h}$ if $\mathrm{O}_{2}$ saturation monitored by pulse oximetry $\left(\mathrm{SpO}_{2}\right)$ was maintained more than $92 \%$ and respiratory rate was less than 35 breaths/min. At $2 \mathrm{~h}$ after extubation, the setting was adjusted to achieve $\mathrm{SpO}_{2}>94 \%$ and respiratory rate $<30$ breaths/min if necessary. The physicians in charge were allowed to use $\mathrm{S} / \mathrm{T}$ mode with different inspiratory and expiratory positive pressure at any time if indicated. NPPV was applied at least for $12 \mathrm{~h}$ and weaned by reducing positive pressure level gradually by $2 \mathrm{cmH}_{2} \mathrm{O}$ while maintaining $\mathrm{SpO}_{2}>94 \%$ and respiratory rate $<30$ breaths $/ \mathrm{min}$. Since the reason why these patients require moderate PEEP for sufficient oxygenation should be overhydration, we dehydrated these patients using diuretics to wean from NPPV while paying strict attentions to hemodynamic stability. Once the PEEP level of $4 \mathrm{cmH}_{2} \mathrm{O}$ and $\mathrm{FIO}_{2}$ equal to or less than 0.5 were achieved, arterial blood gases were analyzed $2 \mathrm{~h}$ later. If $\mathrm{P} / \mathrm{F}$ ratio was above $200 \mathrm{mmHg}$, patients were weaned from NPPV and received $\mathrm{O}_{2}$ mask (total flow, $30 \mathrm{~L} / \mathrm{min} ; \mathrm{FIO}_{2}, 0.5$ ). Weaning from NPPV was considered as successful unless respiratory failure developed for $24 \mathrm{~h}$ after liberation from NPPV, defined as the presence of any of the following criteria: (1) severe hypoxemia with $\mathrm{SpO}_{2}<92 \%$ or $\mathrm{PaO}_{2}<70 \mathrm{mmHg}$ at $\mathrm{FIO}_{2}$ of 0.5 or more, (2) respiratory rate $>35$ breaths $/ \mathrm{min}$, (3) respiratory acidosis (arterial $\mathrm{pH}<7.3$ with a partial pressure of arterial carbon dioxide $\left(\mathrm{PaCO}_{2}\right)>50 \mathrm{mmHg}$ ), (4) clinical signs of respiratory muscle fatigue such as use of accessory muscle and paradoxical motion of the abdomen, (5) inability to remove tracheal secretions, or (6) severe dyspnea.

\section{Criteria for re-intubation}

Patients were immediately intubated if any of the following criteria was unmasked: (1) respiratory or cardiac arrest, (2) respiratory pauses with loss of consciousness or gasping, (3) uncontrolled agitation, (4) massive aspiration, (5) the inability to remove respiratory secretions, or (6) hemodynamic instability unresolved by fluids and vasoactive agents. Furthermore, the patients were reintubated if respiratory failure described above persisted for over $4 \mathrm{~h}$ despite adjustment of ventilator setting and possible medical or physical therapy.

\section{Measurement parameters}

At baseline, demographic data, SOFA score at ICU admission, diagnosis for surgery, and duration of IMV before extubation were recorded. Arterial pressure, heart rate, respiratory rate, and $\mathrm{SpO}_{2}$ were monitored continuously, whereas arterial blood gases were analyzed at 7 a.m. every morning, just before extubation, $2 \mathrm{~h}$ after initiation of NPPV and any time if indicated. The duration of NPPV, the presence of re-intubation or respiratory failure, and the length of ICU stay were also recorded. The primary end-point was the changes of respiratory parameters including $\mathrm{P} / \mathrm{F}$ ratio, respiratory rate, and $\mathrm{PaCO}_{2}, 2 \mathrm{~h}$ after initiation of NPPV compared with those just before extubation. The secondary end-points were the changes of 
hemodynamic parameters (systolic blood pressure and heart rate) after initiation of NPPV, the rate of reintubation, the frequency of respiratory failure and intolerance of NPPV, the duration of NPPV, and the length of ICU stay.

\section{Statistical analysis}

Continuous variables were presented as means \pm standard deviation (SD), or medians and interquartile ranges, and compared by Student's $t$ test for variables with a normal distribution and by Mann-Whitney $U$ test for variables with a non-normal distribution. Categorial valuables were compared by Fisher's exact probability test. A $p$ value of $<0.05$ was considered as statistically significant.

\section{Results}

Fifty-one patients underwent cardiovascular surgery during the study period. Among them, 27 patients were weaned from IMV within $48 \mathrm{~h}$ after surgery, whereas the rest were screened for the eligibility of this study. One patient was excluded from the study because of chronic renal failure requiring hemodialysis. Of another $23 \mathrm{pa}$ tients, 12 patients were weaned from IMV to face mask in accordance with the weaning protocol of our institute after the first SBT at $5 \mathrm{cmH}_{2} \mathrm{O}$ PEEP (Figure 1), of whom 3 patients were re-intubated and 2 of them underwent tracheostomy at 15 and 16 POD. Among other 11 patients, 5 patients did not meet the extubation criteria (second failure). Namely, two patients had tracheostomy at 15 and 21 POD, one patient died at 10 POD due to acute myocardial infarction, and two patients died at 13 and 18 POD due to multiple organ failure with severe sepsis before extubation. After all, six eligible patients who met the extubation criteria after the second SBT were enrolled for this trial. Clinical characteristics of these patients are summarized in Table 1 . Before the successful second SBT, five of six patients failed the first SBT because of hypoxemia (P/F ratio $<200 \mathrm{mmHg}$ ) and another one patient progressed to tachypnea (respiratory rate $\geqq 30$ breaths/min).
In all six patients, NPPV was performed successfully over $12 \mathrm{~h}$ without adjusting ventilator setting. The changes of respiratory parameters are described in Table 2 . The $\mathrm{P} / \mathrm{F}$ ratio increased significantly $2 \mathrm{~h}$ after initiation of NPPV compared with just before extubation (325 \pm $85 \mathrm{mmHg}$ versus $245 \pm 55 \mathrm{mmHg}, p<0.05$ ), while respiratory rate and $\mathrm{PaCO}_{2}$ did not change significantly $(17 \pm 5.5 / \mathrm{min}$ versus $18.2 \pm 6.5 / \mathrm{min}$ and $33.2 \pm 5.3 \mathrm{mmHg}$ versus $34.0 \pm 5.1 \mathrm{mmHg}$, respectively). Hemodynamic parameters including systolic blood pressure and heart rate did not change significantly after initiation of NPPV compared with those before extubation (Table 3). No patients needed re-intubation or developed respiratory failure after application of NPPV. All patients tolerated the whole NPPV procedure. The duration of NPPV was $2.7 \pm$ 0.7 days, and the length of ICU stay was 7.5 (6 to 10) days. However, the rate of re-intubation and the length of ICU stay of these six patients did not reach statistically significant difference compared with those of 12 patients who were extubated to oxygen face mask more than $48 \mathrm{~h}$ after surgeries at low PEEP level of $5 \mathrm{cmH}_{2} \mathrm{O}(0 / 6$ versus 3/12; $p=0.515,7.5$ (6 to 10 ) versus 5.5 (4.5 to 8.5 ) days; $p=0.256$ ). All six patients were discharged from the hospital without any severe consequences.

\section{Discussion}

The present study showed that an application of NPPV after extubation is safe and effective in patients requiring moderate level of PEEP after cardiovascular surgery. In particular, P/F ratio at $2 \mathrm{~h}$ after induction of NPPV improved significantly rather than before extubation. Furthermore, all patients weaned from NPPV successfully without the need of re-intubation and the development of respiratory failure.

NPPV has been used widely now not only in ICU but also in general wards [13], and the efficacy of this technique has been reported in various clinical situations, such as exacerbation of chronic obstructive pulmonary disease (COPD) [14], cardiac pulmonary edema [15], and postoperative respiratory failure $[11,12]$. Although some previous

Table 1 Characteristics of six patients weaned from invasive mechanical ventilation through application of NPPV

\begin{tabular}{|c|c|c|c|c|c|c|c|c|c|c|c|}
\hline No. & Age & Sex & $\begin{array}{c}\text { Height } \\
(\mathrm{cm})\end{array}$ & $\begin{array}{c}\text { Weight } \\
\text { (kg) }\end{array}$ & Diagnosis & $\begin{array}{l}\text { Operative } \\
\text { procedure }\end{array}$ & $\begin{array}{l}\text { Operation time } \\
\text { (h and } \mathrm{min})\end{array}$ & $\begin{array}{l}\text { SOFA } \\
\text { score }\end{array}$ & $\begin{array}{c}\text { Duration of } \\
\text { IMV (day) }\end{array}$ & $\begin{array}{l}\text { Reason for } \\
\text { first failure }\end{array}$ & $\begin{array}{l}\text { Duration of } \\
\text { NPPV (day) }\end{array}$ \\
\hline 1 & 55 & $\mathrm{~F}$ & 161 & 66 & $\mathrm{MR}, \mathrm{TR}$ & MVR, TAP & $7 \mathrm{~h}$ and $04 \mathrm{~min}$ & 8 & 8 & $\mathrm{P} / \mathrm{F}$ ratio $<200 \mathrm{mmHg}$ & 2 \\
\hline 2 & 72 & M & 166 & 66 & Atrial fibrillation & Maze operation & $6 \mathrm{~h}$ and $00 \mathrm{~min}$ & 8 & 3 & $\mathrm{P} / \mathrm{F}$ ratio $<200 \mathrm{mmHg}$ & 2 \\
\hline 3 & 79 & $\mathrm{~F}$ & 148 & 57 & Angina & CABG & $5 \mathrm{~h}$ and $47 \mathrm{~min}$ & 7 & 4 & $\mathrm{P} / \mathrm{F}$ ratio $<200 \mathrm{mmHg}$ & 4 \\
\hline 4 & 71 & M & 161 & 52 & Angina & CABG & $6 \mathrm{~h}$ and $48 \mathrm{~min}$ & 8 & 6 & $\mathrm{RR} \geqq 30 / \mathrm{min}$ & 2 \\
\hline 5 & 63 & M & 170 & 59 & $\begin{array}{c}\text { Stenosis of right } \\
\text { outflow tract }\end{array}$ & $\begin{array}{l}\text { Plasty of right } \\
\text { outflow tract }\end{array}$ & $9 \mathrm{~h}$ and $47 \mathrm{~min}$ & 11 & 8 & $\mathrm{P} / \mathrm{F}$ ratio $<200 \mathrm{mmHg}$ & 3 \\
\hline 6 & 85 & M & 160 & 58 & Angina & CABG & $3 \mathrm{~h}$ and $17 \mathrm{~min}$ & 5 & 3 & P/F ratio $<200 \mathrm{mmHg}$ & 3 \\
\hline
\end{tabular}


Table 2 The changes of respiratory parameters in six eligible patients before and after NPPV application

\begin{tabular}{|c|c|c|c|c|c|c|}
\hline \multirow[t]{2}{*}{ No. } & \multicolumn{2}{|c|}{$\mathrm{P} / \mathrm{F}$ ratio $(\mathrm{mmHg})$} & \multicolumn{2}{|c|}{$\mathrm{RR}$ ( /min) } & \multicolumn{2}{|c|}{$\mathrm{PaCO}_{2}(\mathrm{mmHg})$} \\
\hline & Before & After & Before & After & Before & After \\
\hline 1 & 201.2 & 287.4 & 15 & 12 & 32.6 & 33.0 \\
\hline 2 & 248.3 & 280.4 & 13 & 11 & 33.3 & 36.5 \\
\hline 3 & 246.4 & 298.2 & 16 & 14 & 36.7 & 28.9 \\
\hline 4 & 351.2 & 458.4 & 31 & 25 & 34.1 & 34.7 \\
\hline 5 & 206.6 & 228.6 & 18 & 20 & 41.3 & 40.6 \\
\hline 6 & 219.2 & 398 & 16 & 20 & 25.8 & 25.7 \\
\hline mean $\pm S D$ & $245 \pm 55$ & $325 \pm 85^{*}$ & $18.2 \pm 6.5$ & $17.0 \pm 5.5$ & $34.0 \pm 5.1$ & $33.2 \pm 5.3$ \\
\hline
\end{tabular}

${ }^{*} p<0.05$ compared with before. $\mathrm{P} / \mathrm{F}$ ratio, partial pressure of arterial oxygen tension to inspiratory oxygen fraction ratio; $\mathrm{RR}$, respiratory ratio; $\mathrm{PaCO}{ }_{2}$, partial pressure of arterial carbon dioxide.

studies examined the effect of NPPV to facilitate a weaning from IMV in patients who required long-term ventilator support and suffered from persistent weaning failure [6-8], our study is quite different from these previous studies in some points. Contrary to previous studies which included medial ICU patients with predominantly hypercapnic COPD patients, our study targeted only patients who have risk factors for developing hypoxemic respiratory failure after cardiovascular surgery. Besides, we applied NPPV after extubation in patients who could maintain sufficient oxygenation at PEEP level of $8 \mathrm{cmH}_{2} \mathrm{O}$ but failed at $5 \mathrm{cmH}_{2} \mathrm{O}$ PEEP following our weaning protocol in this study. We guessed that the major reasons why these six patients required moderate PEEP level were atelectasis, overhydration, and cardiogenic pulmonary edema due to the long procedure of cardiac surgery and large amount of transfusion required for perioperative hemodynamic stability. Thus, it is unclear whether this weaning technique can be generalized to other type of hypoxemic respiratory failure patients. However, one recent small randomized controlled study, including 20 patients, demonstrated that NPPV application after early extubation from moderate level of PEEP was beneficial in non-surgical patients with resolving hypoxemic respiratory failure [16]. Furthermore, early application of nasal CPAP after extubation from $7 \mathrm{~cm}$

Table 3 The changes of hemodynamic parameters in six eligible patients before and after NPPV application

\begin{tabular}{lccccc}
\hline \multirow{2}{*}{ No. } & \multicolumn{2}{c}{ Systolic BP $(\mathbf{m m H g})$} & & \multicolumn{2}{c}{ HR (beats/min) } \\
\cline { 2 - 3 } & Before & After & & Before & After \\
\hline 1 & 122 & 113 & & 89 & 78 \\
2 & 145 & 135 & & 94 & 87 \\
3 & 112 & 121 & 79 & 85 \\
4 & 108 & 102 & 82 & 78 \\
5 & 138 & 136 & 61 & 65 \\
6 & 142 & 128 & & 71 & 62 \\
mean \pm SD & $128 \pm 16$ & $123 \pm 13$ & $79 \pm 12$ & $76 \pm 10$ \\
\hline
\end{tabular}

$\mathrm{NPPV}$, noninvasive positive pressure ventilation; $\mathrm{BP}$, blood pressure; $\mathrm{HR}$, heart rate.
$\mathrm{H}_{2} \mathrm{O}$ PEEP was reported to reduce pulmonary morbidity and length of hospital stay following the surgical repair of thoracoabdominal aortic aneurysms [17]. Thus, weaning strategy through NPPV for patients requiring moderate level of PEEP might be beneficial in wide range of hypoxemic respiratory failure, which should be confirmed by a large randomized controlled trial.

Oxygenation improved significantly after the initiation of NPPV compared with before extubation even though the applied PEEP level was the same $\left(8 \mathrm{cmH}_{2} \mathrm{O}\right)$. While the exact mechanisms for this improvement is unknown, some possible mechanisms are considered, such as absence of sedation other than dexmedetomidine, increased patient's activity, and improvement of dorsal ventilation leading to reduced V/Q mismatch. Although this improvement of oxygenation could support the use of this weaning strategy, there are some concerns to apply this technique. Delayed intubation after developing respiratory failure is associated with worse outcome $[18,19]$, thereby re-intubation should not be hesitated if respiratory failure once develops. The protocol to prevent delayed reintubation should be made in all ICU where patients with respiratory failure are treated by NPPV. Tolerance of patients is also one of the key factors in managing NPPV successfully. Although patients were sedated with remifentanil or propofol to increase NPPV tolerance in previous studies [20,21], we used continuous dexmedetomidine infusion, which has little respiratory depressant effects, to relieve discomfort as a routine practice, probably contributing to the high successful rate of NPPV management in our ICU.

There are several limitations to interpret the data herein. First, this study is not a randomized controlled trial but an observational study, and the sample size was too small. It remains unknown whether this technique can reduce the length of mechanical ventilation, the rate of complication relating to IMV, the length of ICU stay, and the mortality compared with the conventional weaning strategy. However, all 6 patients enrolled in this study could wean from IMV through application of NPPV without any progression 
to respiratory failure and the need of re-intubation, while 3 of 12 patients who were liberated from IMV to oxygen face mask were re-intubated even though they passed SBT at the low PEEP level $\left(5 \mathrm{cmH}_{2} \mathrm{O}\right)$. Although the rate of reintubation did not reach significant difference, this might be attributed to the small sample size. Whether this weaning strategy could reduce the rate of re-intubation, it should be evaluated in a randomized controlled trial in the future. Second, we performed two sequential SBT for $4 \mathrm{~h}$ in this study protocol which could be too long procedure, while some weaning guideline recommends SBT should be performed every 24 h [22]. However, there are no evidences as to the appropriate duration of SBT. Finally, there is no rationale for $8 \mathrm{~cm} \mathrm{H}_{2} \mathrm{O}$ of PEEP level at which trachea were extubated in this study. It may be plausible that patients could be liberated from IMV at higher level of PEEP, which should be examined in a future study.

\section{Conclusions}

Application of NPPV after liberation from IMV via tracheal intubation was safe and effective in patients who required moderate level of PEEP for sufficient oxygenation after cardiovascular surgery. The $\mathrm{P} / \mathrm{F}$ ratio improved significantly $2 \mathrm{~h}$ after initiation of NPPV compared with that just before extubation, and all patients could wean successfully without development of respiratory failure and re-intubation. A randomized controlled trial is warranted to confirm the effectiveness of this technique before it is widely used in other ICU.

\section{Abbreviations \\ COPD: chronic obstructive pulmonary disease; CPAP: continuous positive airway pressure; $\mathrm{FIO}_{2}$ : inspiratory oxygen fraction; ICU: intensive care unit; IMV: invasive mechanical ventilation; NPPV: noninvasive positive pressure ventilation; $\mathrm{P} / \mathrm{F}$ ratio: $\mathrm{PaO}_{2}$ to $\mathrm{FlO}_{2}$ ratio; $\mathrm{PaCO}_{2}$ : partial pressure of arterial carbon dioxide; $\mathrm{PaO}_{2}$ : partial pressure of arterial oxygen tension; PEEP: positive end-expiratory pressure; PS: pressure support; SBT: spontaneous breathing trial; SD: standard deviation; SOFA score: sequential organ failure assessment score; $\mathrm{SpO}_{2}$ : $\mathrm{O}_{2}$ saturation monitored by pulse oximetry.}

\section{Competing interests}

The authors declare that they have no competing interest.

\section{Authors' contributions}

TS planned and conducted the study, collected the data, and drafted the manuscript. TK, ST, YM, and YM participated in planning the study design, conducted the study, and helped in drafting the manuscript. JM gave advice for planning the study, coordinated all the study, and helped in drafting the manuscript. SK and NK participated in planning the study design, analyzed the data, and helped in drafting the manuscript. HM helped to coordinate the study, and supervised all parts of the study. All authors read and approved the final manuscript.

\section{Author details}

'Department of Anesthesia, Kawasaki Municipal Hospital, 12-1 Shinkawadori, Kawasaki-ku, Kawasaki-shi, Kanagawa 210-0013, Japan. ${ }^{2}$ Department of Anesthesiology and General Intensive Care Unit, Keio University School of Medicine, 35 Shinanomachi, Shinjuku-ku, Tokyo 160-8582, Japan.

Received: 11 August 2013 Accepted: 8 January 2014

Published: 23 January 2014

\section{References}

1. Esteban A, Anzueto A, Frutos F, Alia I, Brochard L, Stewert TE, Benito S, Epstein SK, Apezteguia C, Nightingale P, Arroliga AC, Tobin MJ: Characteristics and outcomes in adult patients receiving mechanical ventilation: 28-day international study. JAMA 2002, 287:345-355.

2. Esperatti M, Ferrer $M$, Theessen A, Liapikou A, Valencia M, Saucedo LM, Zavala E, Welte T, Torres A: Nosocomial pneumonia in the intensive care unit acquired by mechanically ventilated versus nonventilated patients. Am J Respir Crit Care Med 2010, 182:1533-1539.

3. Kress JP, Pohlman AS, O'Connor MF, Hall JB: Daily interruption of sedative infusion in critically ill patients undergoing mechanical ventilation. N Engl J Med 2000, 342:1471-1477.

4. Brook AD, Ahrens TS, Schaiff R: Effect of a nursing-implemented sedation protocol om the duration of mechanical ventilation. Crit Care Med 1999, 335:1864-1869.

5. Girard TD, Kress JP, Fuchs BD, Thomason JW, Schweickert WD, Pun BT, Taichman DB, Dunn JG, Pohlman AS, Kinniry PA, Jackson JC, Canonico AE, Light RW, Shintani AK, Thompson JL, Gordon SM, Hall JB, Dittus RS, Bernard GR, Ely EW: Efficacy and safety of a paired sedation and ventilator weaning protocol for mechanically ventilated patients in intensive care (Awaking and Breathing Controlled Trial): a randomized controlled trial. Lancet 2008, 371:126-134.

6. Ferrer M, Esquinas A, Arancibia F, Bauer TT, Gonzalez G, Carrillo A, Rodriguez-Roisin R, Torres A: Noninvasive ventilation during persistent weaning failure. Am J Respir Crit Care Med 2003, 168:70-76.

7. Girault C, Daudenthun I, Chevron V, Tamion F, Leroy J, Bonmarchand G: Noninvasive ventilation as a systemic extubation and weaning technique in acute-on-chronic respiratory failure. Am J Respir Crit Care Med 1999, 160:86-92.

8. Nava S, Ambrosino N, Clini E, Prato M, Orlando G, Vitacca M, Brigada P, Fracchia C, Rubini F: Noninvasive mechanical ventilation in the weaning of patients with respiratory failure due to chronic obstructive pulmonary disease. Ann Intern Med 1998, 128:721-728.

9. Wynne R, Botti M: Postoperative pulmonary dysfunction in adults after cardiac surgery with cardiopulmonary bypass: clinical significance and implications for practice. Am J Crit Care 2004, 13:384-393.

10. Christenson JT, Aeberhard JM, Badel P, Pepcak F, Maurice J, Simonet F, Velebit $V$, Schmuziqer M: Adult respiratory distress syndrome after cardiac surgery. Cardiovasc Surg 1996, 4:15-21.

11. Jaber $S$, Chanques $G$, Jung B: Postoperative noninvasive ventilation. Anesthesiology 2010, 112:453-461.

12. Squadrone V, Coha M, Cerutti E, Schellino MM, Biolino P, Occella P, Belloni G, Vilianis G, Fiore G, Cavallo F, Ranieri VM: Continuous positive airway pressure for treatment of postoperative hypoxemia. JAMA 2005, 293:589-595.

13. Plant PK, Owen JL, Elliott MW: Early use of non-invasive ventilation for acute exacerbations of chronic obstructive pulmonary disease on general respiratory wards: a multicenter randomised controlled trial. Lancet 2000, 355:1931-1935.

14. Brochard L, Mancebo J, Wysocki M, Lofaso F, Conti G, Rauss A, Simonneau G, Benito S, Gasparetto A, Lemaire F, Isabey D, Harf A: Noninvasive ventilation for acute exacerbation of chronic obstructive pulmonary disease. $N$ Engl J Med 1995, 333:817-822

15. Peter JV, Moran JL, Phillips-Hughes J, Graham P, Bersten AD: Effect of non-invasive positive pressure ventilation (NIPPV) on mortality in patients with acute cardiogenic pulmonary oedema: a meta-analysis. Lancet 2006, 367:1155-1163.

16. Vaschetto R, Turucz E, Dellapiazza F, Guide S, Colombo D, Cammarota G, Della Corte F, Antonelli M, Navalesi P: Noninvasive ventilation after early extubation in patients recovering from hypoxemic acute respiratory failure: a single-centre feasibility study. Intensive Care Med 2012, 38:1599-1606.

17. Kindgen-Milles D, Muller E, Buhl R, Bohner H, Ritter D, Sandmann W, Tarnow J: Nasal-continuous positive airway pressure reduces pulmonary morbidity and length of hospital stay following thoracoabdominal aortic surgery. Chest 2005, 128:821-828.

18. Epstein SK, Ciubotaru RL: Independent effects of etiology of failure and time to reintubation on outcome for patients failing extubation. Am J Respir Crit Care Med 1998, 158:489-493.

19. Lellouche F: Noninvasive ventilation in patients with hypoxemic acute respiratory failure. Curr Opin Crit Care 2007, 13:12-19. 
20. Constantin JM, Scheider E, Cayot-Constantin S, Guerin R, Bannier F, Futier E, Bazin JE: Remifentanil-based sedation to treat noninvasive ventilation failure: a preliminary study. Intensive Care Med 2007, 33:82-87.

21. Rocco M, Conti G, Alessandri E, Morelli A, Spadetta G, Laderchi A, Di Santo C, Francavia S, Pietropaoli P: Rescue treatment for noninvasive ventilation failure due to interface intolerance with remifentanil analgosedation: a pilot study. Intensive Care Med 2010, 36:2060-2065.

22. Maclntyre NR, Cook DJ, Ely EW Jr, Epstein SK, Fink JB, Heffner JE, Hess D, Hubmayer RD, Scheinhorn DJ: Evidence-based guideline for weaning and discontinuing ventilatory support: a collective task force facilitated by the American College of Chest Physicians; the American Association for Respiratory Care; and the American College of Critical Care Medicine. Chest 2001, 120:375S-395S.

\section{doi:10.1186/2052-0492-2-5}

Cite this article as: Suzuki et al:: Evaluation of noninvasive positive pressure ventilation after extubation from moderate positive end-expiratory pressure level in patients undergoing cardiovascular surgery: a prospective observational study. Journal of Intensive Care 2014 2:5.

\section{Submit your next manuscript to BioMed Central and take full advantage of:}

- Convenient online submission

- Thorough peer review

- No space constraints or color figure charges

- Immediate publication on acceptance

- Inclusion in PubMed, CAS, Scopus and Google Scholar

- Research which is freely available for redistribution 